\title{
Controlled trial of anti-tuberculous chemotherapy for two years in Crohn's disease
}

\author{
G L Swift, E D Srivastava, R Stone, R D Pullan, R G Newcombe, J Rhodes, S Wilkinson, \\ P Rhodes, G Roberts, B W Lawrie, K T Evans, P A Jenkins, G T Williams, G Strohmeyer, \\ G Kreuzpaintner, G A O Thomas, B Calcraft, P S Davies, T J Morris, J Morris
}

\begin{abstract}
One hundred and thirty patients with active symptoms of Crohn's disease were treated in a double blind randomised controlled trial with rifampicin, isoniazid, and ethambutol, or identical placebos for up to two years. All other treatment considered necessary was continued. Analyses were based on 126 patients, 63 in each treatment group. Thirty seven in the active and 30 in the placebo group had previous surgical procedures. There was no difference in concomitant treatment between the two groups. Thirty in the active and 46 in the placebo groups were taking corticosteroids at entry to the trial. Forty eight of 63 patients in the active and 49 of 63 in the placebo group, completed at least 12 months' therapy. Reasons for early withdrawal included pregnancy, adverse reaction, and failure to comply. There was no significant difference in the mean number of months completed between the two groups. Nineteen adverse reactions were recorded for 17 patients in the active group compared with three reactions in patients on placebo. All of the nine patients withdrawn early because of adverse reactions were in the active group. Fifteen patients on active treatment and 14 on placebo had surgery during the trial with no difference in the type of surgery required between the groups. Radiological assessments based on 98 patients at the end of the trial showed no significant differences between groups in changes of extent of disease. More patients developed strictures on placebo compared with active treatment but without a statistically significant difference. No differences were found between groups for the total prednisolone dose or the number of days on which prednisolone dose was $10 \mathrm{mg}$ or above. Serial measurements of body weight and Crohn's disease activity index (CDAI) together with blood values for albumin, haemoglobin, white cell count, and platelets showed no consistent differences between groups. There were occasional significant differences for some of these values between groups, which were not sustained. The trial provides little evidence of tangible benefit from the trial treatment.

(Gut 1994; 35: 363-368)
\end{abstract}

The cause of Crohn's diease (CD) has remained obscure since early pathological descriptions of the condition. ${ }^{1-3}$ While Crohn ${ }^{3}$ and others speculated that the disease may be due to an infection similar to tuberculosis, attempts to isolate and cultivate mycobacteria were unsuccessful.
Recently, however, a number of mycobacterium species ${ }^{4}$ have been isolated from tissue in Crohn's disease. ${ }^{5-7}$ Although the role of mycobacteria and other organisms in CD remains uncertain, ${ }^{89}$ Mycobacterium paratuberculosis is known to cause a granulomatous ileitis in ruminants (Johne's disease) and has been linked with $\mathrm{CD}$ in humans. ${ }^{10}$

Against this background and with reports that anti-tuberculous chemotherapy may have a role in the treatment of $\mathrm{CD}^{11-16}$ we have conducted a double blind clinical trial of anti-tuberculous chemotherapy given for two years, in 130 patients with active disease. The immediate value of this therapy was examined and we plan to follow up its effect on recurrence of disease in the longer term.

\section{Methods}

PATIENTS

One hundred and thirty patients with active symptoms during the previous four months entered this double blind study. They were aged between 16 and 70 years. Diagnosis was based on clinical, histological, and radiological evidence. ${ }^{17}$ Three centres participated in the study; patients from several hospitals in south Wales were referred to the University Hospital of Wales in Cardiff, while others were seen in Gloucester and Dusseldorf.

Exclusion criteria were severe acute disease, toxic megacolon, hepatic or renal impairment, women who were pregnant or planning a pregnancy, and patients taking anticoagulant, anticonvulsant or sulphonylurea treatment. Women were advised of the possible interaction with oral contraceptives and advice about alternative methods given.

\section{DRUGS}

Rifampicin, ethambutol, and isoniazid were chosen after preliminary studies indicated that $M$ paratuberculosis was sensitive to these standard anti-tuberculosis drugs. The in vitro tests were carried out in the Mycobacterium Reference Unit of the Public Health Laboratory Service at the Cardiff Public Health Laboratory using a conventional modal resistance method.

Patients were allocated to treatment groups according to a predetermined randomisation sequence that was stratified by centre only. The admitting clinician was blind to the next treatment in the sequence, which was then dispensed by the pharmacy department. Patients were given either active treatment or identical placebo 
tablets. The dose of rifampicin was $450 \mathrm{mg}$ daily for patients weighing less than $50 \mathrm{~kg}$ and $600 \mathrm{mg}$ for those $50 \mathrm{~kg}$ or more; the dose of isoniazid was $300 \mathrm{mg}$ daily and of ethambutol $15 \mathrm{mg} / \mathrm{kg} /$ day. All other treatment that was considered appropriate for $C D$ was continued as indicated during the trial period, which was designed to last for two years.

\section{ASSESSMENTS}

At the initial visit patients were classified into three groups according to site of disease: (a) ileal or small bowel disease, or both; (b) colonic or perianal disease; and (c) small and large bowel disease.

Assessments were made initially and then at 1 , $2,4,6,9,12,16,20$, and 24 months with additional hospital visits, if required. Weight, routine haematology and biochemistry tests were recorded at each visit; radiology was performed initially if it was not available from the previous six months and at completion of the trial. Additional radiology was carried out during the trial if clinically indicated. Any additional treatment was recorded on a daily diary card, noting particularly the dose of corticosteroids; this was subsequently used to calculate for each patient, the total dose of oral prednisolone for every three months of the study and the number of days for which prednisolone dose was $10 \mathrm{mg}$ or greater; stool frequency and symptoms of abdominal pain were also recorded.

Disease activity was assessed at each visit using the modified Harvey-Bradshaw Crohn's disease activity index - CDAI. ${ }^{18}$

Because ethambutol has been associated with impaired visual acuity, which is heralded by impaired colour discrimination, measurements of this and visual acuity were made at the start of the trial and at six monthly intervals. All patients and their general practitioners were warned of possible side effects from ethambutol. An ophthalmologist was consulted about ocular problems before or during the trial period.

Patient compliance was assessed by an independent nurse using tablet counts and urine checks, at each clinic attendance; the orange discolouration of urine produced by rifampicin was recorded by the nurse but this information was withheld from doctors responsible for patient care. In practice this provided effective 'blinding'.

Early withdrawals occurred because of adverse drug effects, poor compliance, pregnancy or plans for pregnancy, or death. Patients who required surgery during the trial discontinued therapy for about two weeks and then recommenced with their usual dose for the remainder of the trial. If breaks in therapy occurred, the trial period was extended so that 24 months of treatment were given where possible. Because the length of follow up was commensurate with the duration of accrual no arrangements were made for an interim analysis, nor were 'stopping rules' constructed, but surgical intervention and early withdrawals were anticipated in a substantial number. Important points to indicate change in the clinical state were the Harvey-Bradshaw disease activity score, supple- mented by changes in weight, platelet count, and serum albumin. Radiological features, or where appropriate endoscopy or surgical findings were the basis for change in extent of disease.

\section{STATISTICAL METHODS}

The sample size required to achieve adequate power was assessed when the study was planned. The primary objective was to discover if treatment had a favourable effect on the course of the disease over two years. The initial calculation, however, was based on a projected five year proportion remaining in remission of 10 per cent on standard management, increasing to one third on active treatment; a total of 120 patients yielded a power well above 0.8 at $\alpha=0.05$. It was estimated that a comparison based on a continuous outcome measure, CDAI at two years, using the baseline value as covariate, would be more powerful.

Comparisons between groups were made on an intention to treat basis as far as possible; withdrawal of active treatment did not lead to switching to the control group. Initial comparability of groups, and comparisons of outcome variables recorded only at termination, were assessed by standard methods of unpaired $t$, Mann-Whitney, $\chi^{2}$ or Fisher tests as appropriate. Serial changes in clinical scores, haematological parameters, and drug doses were compared between groups by analysis of variance, using the appropriate baseline value as covariate. Correspondingly, data on whether anti-diarrhoeal drugs were used were analysed by the MantelHaenszel method.

\section{Results}

Analyses are based on 126 of 130 patients admitted to the study. The remaining four patients were excluded because their diagnosis was revised to ulcerative colitis or because com-

TABLE I Details of patients entering the study

\begin{tabular}{lcc}
\hline & Active $(n=63)$ & Placebo $(n=63)$ \\
\hline Sex: & & \\
Male & 27 & 31 \\
Female & 36 & 32 \\
Extent: & 18 & 22 \\
Small bowel & 19 & 14 \\
Large bowel & 26 & 27 \\
Small+large & 17 & 24 \\
Smoking: & 16 & 13 \\
$\quad$ Non-smoker & 30 & 26 \\
Former smoker & 37 & 30 \\
Current smoker & 26 & 33 \\
Previous surgery: & $36 \cdot 7(13 \cdot 1)$ & $36 \cdot 3(13 \cdot 1)$ \\
Yes & $7 \cdot 0(7 \cdot 6)$ & $7 \cdot 9(7 \cdot 2)$ \\
No & $65 \cdot 8(13 \cdot 0)$ & $63 \cdot 6(12 \cdot 6)$ \\
Age $(y)$ & $23 \cdot 5(3 \cdot 8)$ & $22 \cdot 8(4 \cdot 2)$ \\
Duration (y) & $13 \cdot 2(1 \cdot 8)$ & $13 \cdot 0(1 \cdot 6)$ \\
Weight $(\mathrm{kg})$ & $9 \cdot 4(3 \cdot 0)$ & $10 \cdot 0(3 \cdot 0)$ \\
Quetelet index $\left(\mathrm{kg} / \mathrm{m}^{2}\right)$ & $385(140)$ & $399(143)$ \\
Haemoglobin $(\mathrm{g} / \mathrm{dl})$ & $41 \cdot 7(5 \cdot 3)$ & $41 \cdot 1(4 \cdot 5)$ \\
White cell count $\left(\times 10^{9} / \mathrm{l}\right)$ & $7 \cdot 1(4 \cdot 5)$ & $6 \cdot 9(4 \cdot 7)$ \\
Platelets $\left(\times 10^{9} / \mathrm{l}\right)$ & $11 \cdot 8(11 \cdot 0)$ & $12 \cdot 7(9 \cdot 6)$ \\
Albumin $(\mathrm{d} / \mathrm{dl})$ & $(30$ patients $)$ & $(46 \mathrm{patients})$ \\
CDAI $($ Harvey-Bradshaw) & & \\
Prednisolone dose $(\mathrm{mg} / \mathrm{day})$ & &
\end{tabular}

Demographic, clinical, and laboratory data for 126 patients with Crohn's disease at entry to a two year trial of anti-tuberculous chemotherapy. Quantitative variables summarised by mean and $\mathrm{SD}$. Numbers of patients receiving prednisolone in the groups differed significantly $\chi^{2} 6 \cdot 72, p<0 \cdot 01$. CDAI $=$ Crohn's disease activity index. 
TABLE II Number of months of trial treatment completed

\begin{tabular}{ccc}
\hline & $\begin{array}{l}\text { Group 1 active } \\
(n=63)\end{array}$ & $\begin{array}{l}\text { Group 2 placebo } \\
(n=63)\end{array}$ \\
\hline Months & & \\
$0-6$ & 12 & 11 \\
$7-12$ & 3 & 3 \\
$13-18$ & 13 & 6 \\
$19-24$ & 35 & 43 \\
\hline
\end{tabular}

pletion data for the end of the trial were not yet available. Sixty three received active antituberculous chemotherapy (group 1) and 63, the matching placebo regimen (group 2).

The two groups showed initial comparability in terms of sex, extent of disease, smoking habits, mean age, duration of disease, height, weight, Quetelet index, haemoglobin, white cell and platelet counts, serum albumin, and CDAI (Table I).

Thirty seven patients in group 1 and 30 patients in group 2 had previous surgical procedures, including a right hemicolectomy in 26 , ilectomy in 27 , partial or total colectomy in 14 , and small bowel resections in $11 ; 30$ patients had had perianal surgery.

Seventy six patients were taking prednisolone at entry to the study (30 in group 1 and 46 in group $2, \chi^{2} 6.72, p<0.01$ ). The mean daily dose of oral prednisolone in those taking this drug at entry was similar in the two groups (Table I). Twenty seven patients were taking sulphasalazine, 53 mesalazine, 21 azathioprine, 6 oral metronidazole, and 25 anti-diarrhoeal drugs. There was no difference in concomitant therapy between the two groups.

Smoking habits were assessed for all patients; 41 had never smoked, 56 were current smokers, and 29 former smokers.

Forty eight of 63 patients in group 1 and 49 of 63 in group 2 completed at least 12 months of therapy (Table II). Table III gives the reasons for early withdrawal. There was no significant difference in the number of months completed. Thirty nine patients ( 24 in group 1 and 15 in group 2) had one or more breaks in their treatment period.

\section{ADVERSE EVENTS}

Nineteen adverse reactions were recorded for 17 patients in group 1 compared with three reactions in three patients in group 2. All of the nine patients withdrawn early because of adverse reactions were in the active group; the remainder were able to recommence trial treatment.

\section{DETAILS OF ADVERSE REACTIONS}

Three deaths that occurred during the study were unrelated to Crohn's disease or the trial treatment. One patient had a pulmonary embolus after a hip fracture, one a cerebrovascular accident, and the third died of severe postinfluenzal pneumonia.

\section{SURGERY}

Fifteen patients on active treatment and 14 on placebo had surgery during the trial period. Surgery was planned in a further 17 patients
TABLE III Reasons for early withdrawal from study

\begin{tabular}{lll}
\hline & $\begin{array}{l}\text { Group 1 active } \\
(n=63)\end{array}$ & $\begin{array}{l}\text { Group 2 placebo } \\
(n=63)\end{array}$ \\
\hline Normal completion at 24 & & \\
$\quad$ months & 35 & 41 \\
Adverse drug reactions & 9 & 0 \\
Poor compliance & 9 & 9 \\
Severe/complex Crohn's disease & 2 & 7 \\
$\begin{array}{l}\text { Pregnancy or desire to become } \\
\text { pregnant }\end{array}$ & 5 & 3 \\
$\begin{array}{l}\text { Severe intercurrent illness } \\
\text { Patient died }\end{array}$ & 1 & 2 \\
\hline
\end{tabular}

(seven on active and 10 on placebo) at the end of the trial period. There were no differences in the frequency or type of surgery required between the two groups.

\section{RADIOLOGY}

Pretrial radiological assessment showed an excess in the controls with small bowel abnormality, with or without large bowel involvement. Strictures and non-perianal fistulas were equally common in both groups.

Post treatment radiology was available in 98 patients. Overall the extent of disease after active treatment decreased in nine, increased in three, and remained unchanged in 37; with placebo 11 decreased, four increased, and 34 stayed the same. The prevalence of strictures increased from $19 / 49(31 \%)$ to $24 / 49$ (41\%) with placebo but only $19 / 50(38 \%)$ to $20 / 50(40 \%)$ with active treatment. Conversely there was a slight increase in fistulas in the active group. These figures, however, did not reach statistical significance and overall radiological assessment showed no evidence of clinically significant advantage for the active treatment group.

\section{CORTICOSTEROID REQUIREMENT}

In each group, 54 of 63 patients required prednisolone at some time during the trial period. No clear differences were found between the groups for total prednisolone dose or the number of days on which prednisolone dose was $10 \mathrm{mg}$ or above (Fig 1). Because the number of patients taking prednisolone was different in the two groups at entry to the trial, the disease activity was analysed incorporating prednisolone dose at entry as an additional covariate and results showed no quantitative difference between groups.

TABLE IV Effect of treatment on weight and haematological measurements

\begin{tabular}{|c|c|c|c|c|c|}
\hline Month & $\begin{array}{l}\text { Body } \\
\text { weight } \\
\text { (kg) }\end{array}$ & $\begin{array}{l}\text { Haemoglobin } \\
(\mathrm{g} / \mathrm{dl})\end{array}$ & $\begin{array}{l}\text { White cell } \\
\text { count } \\
\left(\times 10^{9} / l\right)\end{array}$ & $\begin{array}{l}\text { Platelets } \\
\left(\times 10^{9} / l\right)\end{array}$ & $\begin{array}{l}\text { Albumin } \\
(\mathrm{g} / d l)\end{array}$ \\
\hline $\begin{array}{r}1 \\
2 \\
4 \\
6 \\
9 \\
12 \\
16 \\
20 \\
24\end{array}$ & $\begin{array}{l}-0.03 \\
-0.11 \\
-1.27 \\
-0.72 \\
-2.11^{\star} \\
-2.16^{\star} \\
-0.68 \\
-0.88 \\
-0.86\end{array}$ & $\begin{array}{l}-0.25 \\
-0.12 \\
+0.09 \\
-0.24 \\
-0.16 \\
-0.17 \\
+0.23 \\
+0.19 \\
+0.34\end{array}$ & $\begin{array}{l}-1.34 \star \star \\
-0.85 \\
-0.37 \\
+0.44 \\
-0.17 \\
+0.15 \\
+0.08 \\
+0.54 \\
+0.96\end{array}$ & $\begin{array}{l}-28 \cdot 1 \\
-49 \cdot 1 \star \star \star \\
-40 \cdot 9 \\
-25 \cdot 5 \\
-10 \cdot 2 \\
-3 \cdot 0 \\
-8 \cdot 0 \\
-2 \cdot 5 \\
-15 \cdot 6\end{array}$ & $\begin{array}{l}-0.86 \\
+0.02 \\
-0.01 \\
-1.20^{\star} \\
-1.27^{\star} \\
-0.61 \\
-0.65 \\
-1.10 \\
-1.70^{\star}\end{array}$ \\
\hline
\end{tabular}

Effect of trial treatment during the 24 months on body weight and haematological parameters, estimated by analysis of covariance. Positive values correspond to an increase with active treatment compared with placebo and vice versa $\left({ }^{\star} p<0 \cdot 05 ;{ }^{\star \star} p<0 \cdot 01\right.$ ${ }_{\star \star \star} \mathrm{p}<0.001$ ). 

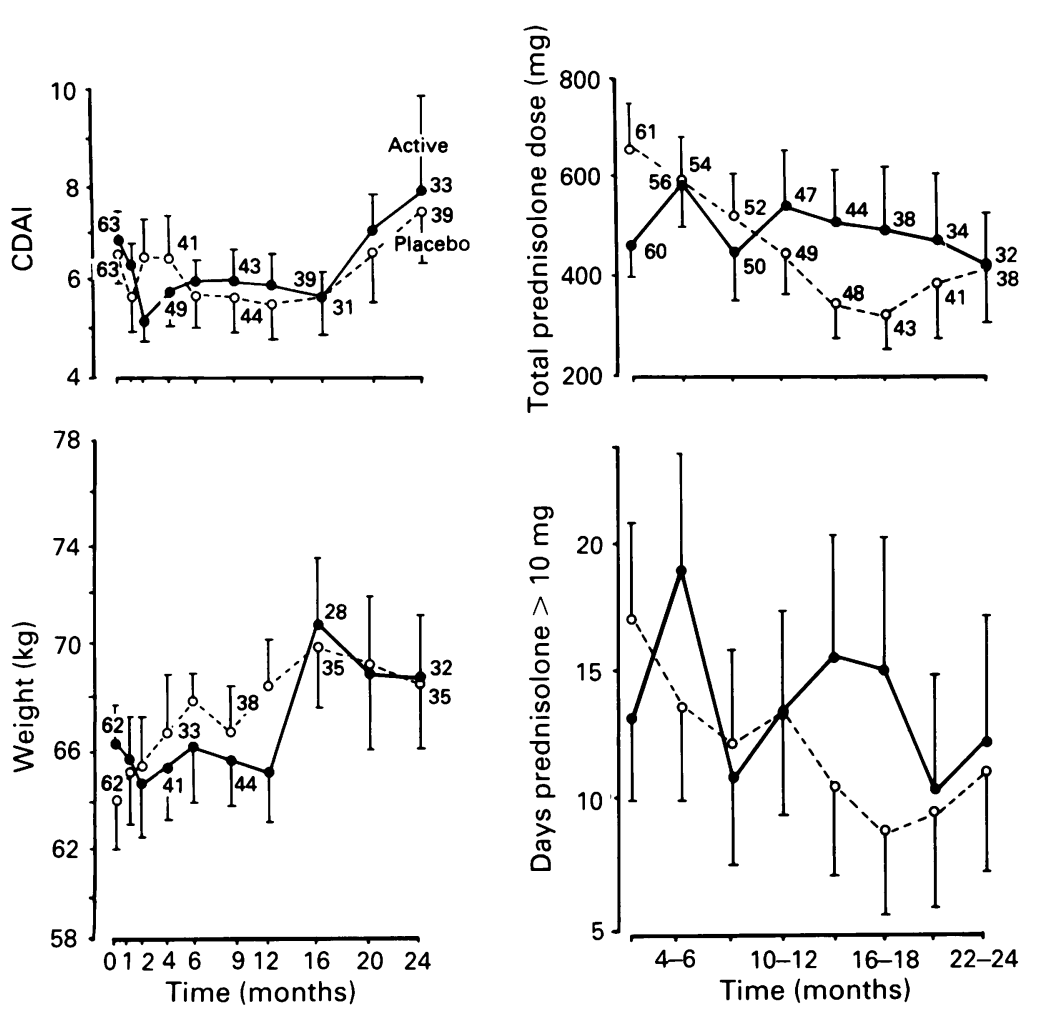

Figure 1: Serial measurements of patients' Crohn's disease activity index ${ }^{18}(C D A I)$, weight ( $\mathrm{kg}$ ), total prednisolone dose ( $\mathrm{mg}$ ) in each three month period, and the number of days the daily dose of prednisolone was $>10 \mathrm{mg}$ in each three month period over 24 months in patients with Crohn's disease given active anti-tuberculous chemotherapy _- or identical placebo . ....... O. Sixty three patients started the trial in each group but subsequent values were based on reduced numbers of patients as shown in the figures. Numbers of patients in both prednisolone figures are the same.
OTHER DRUGS

In the active group there was a trend towards a decrease in the need for sulphasalazine, azathioprine, and metronidazole and anti-diarrhoeal drugs in the medium term and possibly an increase in prednisolone requirement, although this never reached statistical significance.

The study provides little evidence of tangible benefit from the trial treatment. No difference was found for radiological assessment and there was no consistent beneficial effect on the disease activity score or its constituent parts, nor any decrease in recourse to other drugs.

\section{Discussion}

We have examined the effect of triple antituberculous chemotherapy in a trial of 126 patients with active Crohn's disease. No evidence of benefit in terms of disease activity, radiological assessment, need for surgery, corticosteroids or other treatment was shown. The study was double blind with all clinical assessments made without knowledge of the patient's treatment group; the blinding procedures that withheld information about discolouration of urine from doctors participating in the study were very effective. Treatment was not taken for the whole two year period in all patients, but only 12 of 63 on active drugs had less than six months' therapy.

We are very conscious of the considerable problems associated with clinical trials in Crohn's disease. Although patients were randomised, there were significantly more patients receiving prednisolone in the placebo group on entry to the trial. In theory this may have affected the outcome; the placebo group could have fared better because of the benefits of their prednisone, or conversely worse because they represented more severe disease. Thus a separate analysis of disease activity was made with the initial prednisolone dose as an additional covariate, but this showed no differences. The large variation in clinical features between individual patients makes it difficult to define a homogeneous group. It would also be unethical to discontinue other treatment thought to be necessary in patients with active disease over a prolonged period, and the effect of such treatment could mask any additional benefit from the 'trial drug' under investigation. The problem is further compounded by the unpredictable variations in disease activity that seem to occur irrespective of therapy in patients followed up over a long period.

Perhaps a more fundamental problem is related to the interpretation of results from trials of anti-tuberculous therapy in Crohn's disease. If we begin with the proposition that a mycobacterium is the cause of this condition, improvement in symptoms after appropriate therapy does not necessarily support the proposition. Likewise, failure to improve with treatment does not exclude the possible role of mycobacteria initiating the disease. Symptoms in patients with Crohn's disease are a result of inflammation in the bowel wall and anatomical abnormalities that may develop, such as strictures, fistulas, and abscesses. Although anti-tuberculous chemo- 

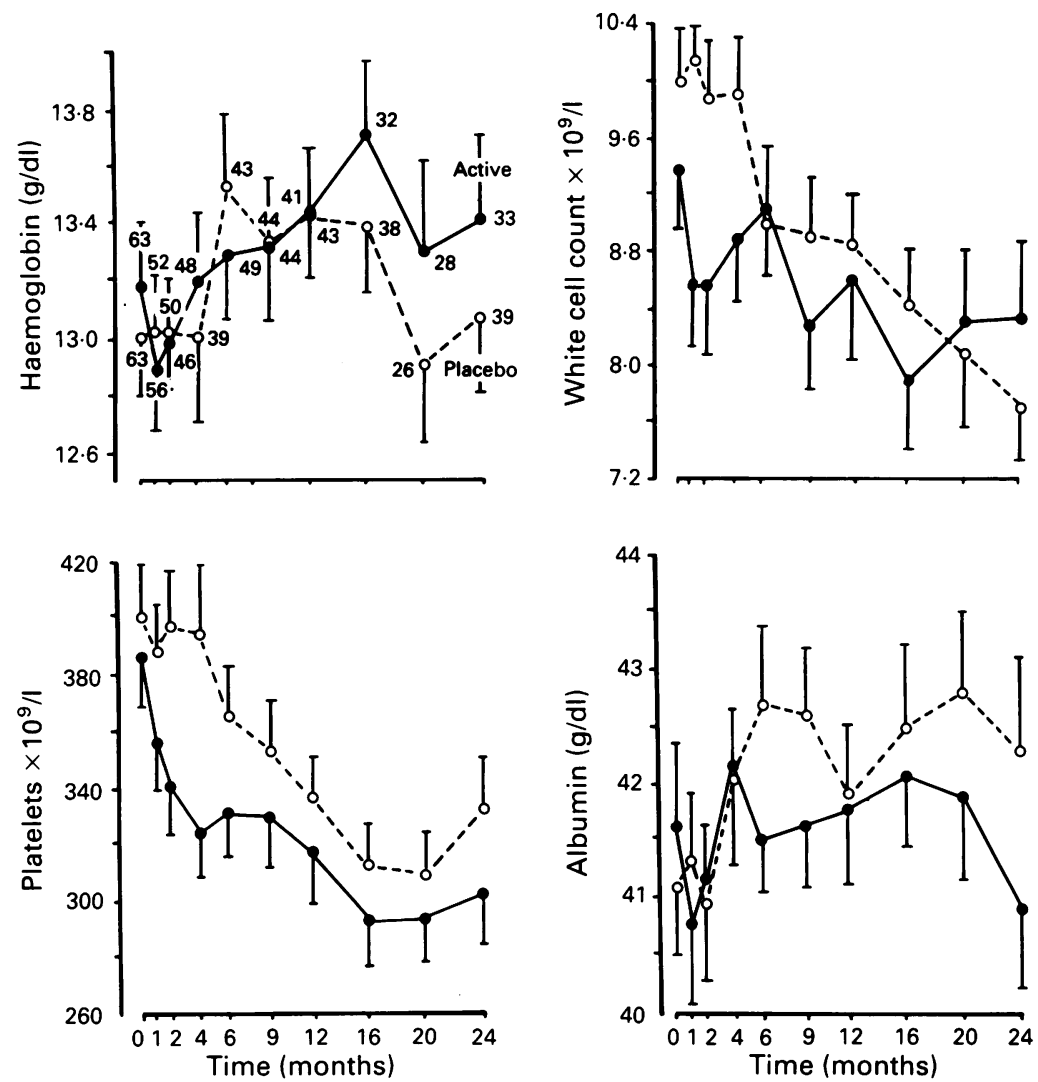

Figure 2: Serial measurements of haemoglobin, white cell count, platelet count, and albumin over 24 months in patients with Crohns disease given active anti-tuberculous chemotherapy or identical placebo $\bigcirc \ldots . . .$. . Sixty three patients started the trial in each group but subsequent values were based on reduced numbers of patients, which are identified in the haemoglobin figure. Means with standard errors are given.

therapy may eradicate mycobacteria it would also affect secondary infection in diseased areas, which may in turn be partly responsible for 'activity'. Symptoms as a result of bowel strictures, however, are unlikely to change substantially, although it is possible that antituberculous chemotherapy may affect different sites in the gastrointestinal tract in a variable way. A parallel may be drawn with pulmonary tuberculosis where bronchial strictures may predispose to secondary infections in patients with active tuberculosis. Although anti-tuberculous chemotherapy will eradicate the tubercle bacillus, it will have little effect on the strictures and associated secondary infections. Although assessments of chemotherapy directed at the causative organism are fraught with these difficulties, the absence of any clear benefit during the time therapy is given makes support for the treatment difficult to justify. Extension or recurrence of Crohn's disease after a period of treatment may be better indicators of a therapeutic effect on the underlying process, but evidence for this would require patients to be followed up for several years.

The possibility that Crohn's disease is caused by a mycobacterium is attractive. It is a chronic inflammatory disease associated with spontaneous relapse and remission, following a clinical course that is not unlike other conditions caused by mycobacteria. Only recently have mycobacteria been identified in Crohn's tissue ${ }^{79-21}$ with positive results in between one and two thirds of cases. ${ }^{922}$ Their presence, however, does not necessarily point to a causative role; diseased bowel may provide a favourable environment for a range of organisms, including mycobacteria, which are simply secondary invaders. Mycobacteria have also been isolated from the gut in other conditions, including ulcerative colitis and from surgical resections of gut. ${ }^{6}$ Some years ago, a group of anaerobes were isolated from the stools of patients with Crohn's disease and a causative role was suggested. ${ }^{23}{ }^{24}$ Subsequent findings, however, showed they were only present in two thirds of cases with evidence of their presence also in some patients with ulcerative colitis and controls; the situation is similar to the current position with $M$ paratuberculosis as the organism is not present in all samples of Crohn's tissue and is found in some controls. A firmer basis for implication of mycobacteria in a causative role would come from controlled trials showing a definite clinical response in patients with active disease with a longterm reduction in recurrence after the treatment.

Studies with anti-tuberculous chemotherapy in Crohn's disease have given conflicting results. There have been anecdotal reports of benefit in individual patients given triple or quadruple chemotherapy. ${ }^{12-14}$ Two open studies ${ }^{11} 15$ with a total of 26 patients showed encouraging results. In one study, ${ }^{15}$ all six patients showed healing of fistulas, reduction in CDAI, and withdrawal of steroids after two to four months' treatment with rifabutin $300 \mathrm{mg}$ daily and streptomycin 1 gram IM 5 days/week. In the second pilot study, Hampson et al found that after quadruple therapy with rifampicin, ethambutol, isoniazid, and either pyrazinamide or clofazimine, 10 of 20 patients were in remission after nine months' treatment; 10 stopped taking steroids, and six had required surgery, five of them for intestinal strictures.

There has been only one other controlled trial of anti-tuberculous drugs ${ }^{16}$ in which 40 patients with severe active Crohn's disease were randomised to nine months' treatment with either ethambutol, rifampicin, dapsone, and clofazimine or placebo. All patients were given methylprednisolone for up to eight weeks before trial treatment to achieve remission. Sixty eight per cent of those receiving placebo and $17 \%$ receiving active treatment relapsed during the study.

There have also been a number of reports in which anti-mycobacterial treatment was found to be ineffective. In a double blind cross over trial $^{25} 14$ of 27 patients completed 12 months each of rifampicin $10 \mathrm{mg} / \mathrm{kg}$ with ethambutol 15 $\mathrm{mg} / \mathrm{kg}$ and placebo. No differences were found for the two treatment periods. With a similar drug regimen Rutgeerts ${ }^{26}$ found no effect on recurrent Crohn's disease in 16 patients treated for six months after ileocolonic resection. Jarnerot $^{27}$ also reported quadruple antituberculous therapy to be ineffective in five patients treated for eight to 13 months.

The correlation between in vitro sensitivity of tubercle bacilli to anti-tuberculosis drugs and the in vivo response to treatment with those drugs has been established by many controlled clinical trials. This is not the case with disease due to other mycobacteria. Organisms of the Avium intracellulare complex for example are highly 
resistant in vitro to rifampicin and ethambutol but a significant number of patients respond satisfactorily to these drugs. The mode of action of the drugs is thought to be the same but the mechanism of resistance must be different. Thus even when a mycobacterial cause has been clearly defined, in vitro sensitivity tests are not necessarily a reliable guide. The role of mycobacteria in Crohn's disease remains to be defined but because in vitro tests suggested that $M$ paratuberculosis was sensitive to some antituberculosis drugs a clinical trial was warranted.

The primary objective of this trial was to examine whether there was a net benefit for patients given anti-tuberculous chemotherapy. It could only be expected to answer 'whether' the treatment had such an effect rather than 'how'. The absence of any apparent benefit, however, in these patients treated for up to 24 months, certainly fails to support the hypothesis that mycobacteria play an important part in the pathogenesis of this disease. Should subsequent follow up of the groups also fail to show any difference in disease recurrence, the hypothesis would be further weakened.

Dr Lynne Beck, consultant ophthalmologist, advised on the management of several patients with visual symptoms during the trial. Mrs Jane Voisey and Mrs Mary Fielder gave assistance with co-ordinating the trial. The Crohn's in Childhood Research
Association (CICRA) helped with financial support. Ciba Geigy and Lederle respectively provided Rifinah (rifampicin, isoniazid) and ethambutol with identical placebo tablets. Ethical approva was obtained from ethical committees in each of the centres taking part and written informed consent obtained from all patients.

1 Dalziel TK. Chronic interstitial enteritis. BMf 1913; 2: 106870.

Moschcowitz E, Wilensky AO. Non-specific granulomata of the intestine. Am F Med Sci 1923; 166: 48-66.

3 Crohn BB, Ginburg L, Oppenheimer G. Regional enteritis - a pathologic and clinical entity. $\mathcal{F A M A}$ 1932; 99: 1323-9.

4 Burnham WR, Lennard-Jones JE, Stanford JL, Bird RG Mycobacteria as a possible cause of inflammatory bowel disease. Lancet 1978; ii: 693-6.

5 Chiodini RJ, Van Kruiningen HJ, Thayer WR, Merkal RS, Coutu JA. Possible role of mycobacteria in inflammatory bowel disease. Dig Dis Sci 1984; 29: 1073-9.

6 Collins J, Beaman B, Arthur M, Gitnick G. Isolation of mycobacteria from intestinal tissues. Gastroenterology 1986; 90: 1377
7 Tytgat GNJ. The aetiology of Crohn's disease. Int $\mathcal{f}$ Colorect Dis 1986; 1: 188-92.

8 Stanford JL, White SA, Burnham WR, Lennard-Jones JE, Bird RG. Mycobacteria and inflammatory bowel disease. Lancet 1979; i: 444.

9 Graham DY, Markesich DC, Yoshimura HH. Mycobacteria and inflammatory bowel disease; results of culture. Gastroenterology 1987; 92: 436-42.

10 Morgan KL. Johne's and Crohn's: chronic inflammatory bowel diseases of infectious aetiology? Lancet 1987; i: 1017-9.

11 Hampson SI, Parker MC, Saverymuttu SH, Joseph AE, McFadden J-JP, Hermon-Taylor J. Quadruple anti9 months of a pilot study in 20 patients. Aliment Pharm Ther 9 months of a pilo

12 Warren JB, Rees HC, Cox TM. Remission of Crohn's diease with tuberculous chemotherapy. $N$ Engl f Med 1986; 314: 182

13 Schulz MG, Rieder HL, Hersh T, Riepe S. Remission of Crohn's disease with antimycobacterial chemotherapy. Lancet 1987; ii: 1391-2.

14 Picciotto A, Gesu GP, Schito GC, Testa R, Varagona G, Celle G. Antimycobacterial chemotherapy in 2 cases of inflammatory bowel disease. Lancet 1988; ii: 536-7.

15 Thayer WR, Coutu JA, Chiodini RJ, Van Kruiningen HJ. Use of rifabutin and streptomycin in the therapy of Crohn's of rifabutin and streptomycin in the the
disease. Gastroenterology 1988; 94: A458.

16 Kohn A, Prantera C, Mangiorotti R, Luzi C, Andreoli A. Antimycobacterial therapy and Crohn's disease; a randomised placebo controlled trial. Gastroenterology 1992; 102: A647.

17 Lennard-Jones JE. Classification of inflammatory bowel disease. Scand $\mathcal{F}$ Gastroenterol 1989; 24 (suppl 170): 2-6.

18 Harvey RF, Bradshaw JM. A simple index of Crohn's disease activity. Lancet 1980; ii: 514 .

19 Chiodini RJ, Van Kruiningen HJ, Merkal RS, Thayer WR Jr, Coutu JA. Characteristics of an unclassified mycobacterium species isolated from patients with Crohn's disease. $f$ Clin Microbiol 1984; 20: 966-71.

20 McFadden JJ, Butcher PD, Chiodini RJ, Hermon-Taylor J. Crohn's disease isolated mycobacteria are identical to Crohn's disease isolated mycobacteria are identical to
Mycobacterium paratuberculosis, as determined by DNA Mycobacterium paratuberculosis, as determined by DNA probes that distinguish between

21 Collins J, Beaman B, Brooks D, Arthur M, Gitnick G. A prospective study of mycobacteria in Crohn's disease. Gastroenterology 1987; 92: 1352 .

22 Sanderson JD, Moss MT, Tizard MLV, Hermon-Taylor J. Mycobacterium paratuberculosis DNA in Crohn's disease tissue. Gut 1992; 33: 890-6.

23 Wensinck F. Faecal flora of crohn's patients. In: Weterman IT, Penã AS, Booth CC, et al (eds). The management of

24 Mayberry J, Rhodes J, Matthews N, Wensinck F. Serum antibodies to anaerobic coccoid rods in patients with Crohn's disease or ulcerative colitis and in medical and nursing staff. BMF 1981; 282: 108 .

25 Schaffer JL, Hughes S, Linaker BD, Baker RD, Turnberg LA. Controlled trial of rifampicin and ethambutol in Crohn's disease. Gut 1984; 25: 203-5.

26 Rutgeerts P, Vantrappen J, Van Isveldt J, Gebees K. Rifabutin therapy in patients with recurrent Crohn's disease after ileocolic resection. Gastroenterology 1988; 94: A391.

27 Jarnerot G, Rolny P, Wickbom G, Alemayehu G. Antimycobacterial therapy ineffective in Crohn's disease after a year. Lancet 1989; i: 164-5. 